\title{
A NOTE ON THE DIGITAL EXAMINATION OF THE NOSE.
}

\author{
By Dan McKenzie, M.D., \\ Assistant Surgeon Central London Throat and Ear Hospital.
}

Perhaps the advisability of supplementing by palpation with the finger the information we obtain by an inspection of the nose is not so frequently remembered as it ought to be. This remark applies, of course, only to the examination through the anterior nares. Without doubt the causes which have led to the neglect of such a useful source of information have been, firstly, the physical difficulty, often indeed insuperable, of inserting the finger deep enough in the nose to feel anything at all ; and secondly, the knowledge that a digital examination through the anterior nares always produces great discomfort and sometimes actual pain.

On the other hand, it cannot be denied that on occasions when circumstances are quite favourable-the nasal passages wide, the patient under an anæsthetic, etc.-the opportunity is too often let slip. And experience teaches that patient and gentle perseverance assiduously practised soon confers the knack of being able to insert the finger into even narrow nostrils with very little discomfort to the patient. Further, if the patient is under an anæsthetic nothing short of considerable physical disproportion between the examiner's finger and the nasal passage should deter him from making an attempt. Without an anæsthetic the examination is no more than uncomfortable unless the finger is pushed in with a brusque determination to carry out the examination at all hazards.

The method generally recommended is as follows: The little finger is always employed, and as it is, save in septal palpation, inserted with the palmar surface turned towards the external wall of the nose, the right hand must be used for the right nostril, and the left for the left. The finger should be well lubricated. The surgeon stands in front and a little to one side of his patient, with his free hand on the top of the patient's head to prevent it being withdrawn at a critical moment. At first sight it might be supposed that the chief obstacle to the passage of the finger would be the vestibular region with its circumscribed cutaneous orifice, but this is not the case. Even small and collapsed alæ are capable of considerable dilatation by the finger if plenty of time be givell. 'The real isthmus lies at the entrance to the osseous nares, where, that is, the cavity is ringed round by the bony floor below, the 
sharp edge of the superior maxilla with its ascending process to the outer side and above, and the septum mesially. Here it is that the patient feels most pain, particularly if the insertion is being carried out too hurriedly. In many cases when the finger is canght in this ring gentle pressure against the septum, cartilaginous at this point, will push it to one side sufficiently to enable the finger to pass. If such gentle pressure is ineffective then further attempts should be abandoned. The septal cartilage is often very thin, and to risk its fracture would be mpardonable. Haring once safely traversed the strait and narrow part the bulbous fingerend comes to lie in a roomier cavity, while the isthmus is occupied hy the less bulky parts of the finger proximal to the last phalangeal joint. The examiner is now sensible that he has reached the middle meatus by feeling the pressure of the hard, rounded, lower whe of the middle turbinal against the upper side of his finger, while below he will be able to make out the superior surface of the inferior turbinal body. Under ordinary conditions of health and normal structures the finger can be pushed but a little further back, its onward progress being prevented by the gradual convergence of the nasal walls. But in disease, particularly in ethmoidal softening and suppuration, where the middle turbinal is carious, destroyed, or flattened against the septum, it is frequently possible to reach as far back as the posterior ethmoidal region, and so to interrogate the lateral wall of the middle meatus along its whole extent.

The finger is steadily pressed against every part of the nose with which it comes into contact. In health this pressure everywhere meets with smooth mucous membrane and definite resilient resistance. Nowhere can the surface be breached. But in ethmoidal disease even gentle pressure breaks down the softened and boggy tissues, so that, as the finger palpates here and there along the region, a well-defined mental picture is quickly formed portraying the extent, and even, in some degree, the depth of the disintegration. And curetting will then be carried out with a confidence and accuracy, absent when one has to rely upon inspection alone. After several strokes of the curette the finger can again be inserted, and so the operation conducted from start to finish under safe and easy guidance. Further, in cases where the disease is limited to one particular area of the ethmoidal labyrinth, the information obtained by palpation enables us to restrict our activity to that area, and to that area alone.

When, in cases of ethmoidal disease, we know or suspect that 
the antrum is likewise affected, the finger can be made to break through the membranous diaphragm in which lies the slit-like ostium maxillare. Thus we can actually enter the antral cavity, and occasionally obtain information as to the state of its lining membrane. Through the opening so made polypi, when present, will be felt as pulpy, slippery bodies. And throngh this opening also, enlarged by the curette if necessary, the antrum can subsequently be washed out, and in some cases-not, of course, in all-the patient may thus be saved the ordeal of a more extensive and severe operation. I have never found any harm follow this proceeding even when the antrum contained no pus, for in these cases the diaphragm quickly closes again.

Palpation of the septum is particularly useful in performing the operation of submucous resection. In order to feel towards the middle line the finger is, of course, turned so that its sensitive anterior surface faces in that direction. Thus the left hand must be used for the right nostril, and vice-versî. During the operation, after the septal cartilage and a portion of the vomer comprising the anterior deflecting portions of the septum have been removed, we are frequently a little puzzled to know whether or not the posterior regions are quite patent. In this quandary no method of examination has in my experience proved so valuable as palpation. Time and again it has happened that inspection under even brilliant illumination has failed to give warning of the presence of a bony spur or deflection lying very far back and obstructing the nasal passage more or less completely. The absence of the anterior portions of septum permits of the insertion of the little finger much more easily than under ordinary conditions, and the posterior obstruction can then be located to a nicety, and its entire removal through the window in the muco-perichondrium ensured. In these cases the insertion of the finger is quite safe on the unwounded side, but on the wounded side care must be exercised not to let the tip of the finger catch in the muco-perichondrial flap as it is passed back.

In all cases of tumour or ulcer in the nose, a careful attempt to palpate the lesion should be made, and it will generally be found that the information so obtained influences the diagnosis very materially.

It is, of course, true that when the examiner possesses thin fingers, digital palpation of the nose is easy, and so for the rhinologist to belong to the "lean and hungry" tribe is a very present advantage. 